\title{
Soft Tissue Cancer Management: Isolated Limb Infusion for Sarcoma
}

\author{
Jyri Teras ${ }^{a, c}$ Andrus Mägi ${ }^{b}$ Marina Teras ${ }^{a, c}$ Pille Patac, ${ }^{c}$ Roland M. Teras ${ }^{a}$ \\ Neena Randhawa ${ }^{\mathrm{e}}$ Kristjan Kalling ${ }^{a}$ \\ ${ }^{a}$ North Estonian Medical Centre Foundation, Tallinn, ${ }^{\mathrm{b}}$ Tartu University Clinic, Tartu, ${ }^{\mathrm{c}}$ Tallinn University of

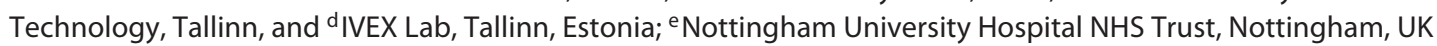

\section{Keywords}

Isolated limb infusion · Soft tissue sarcoma - Melphalan · Actinomycin D

\section{Abstract}

Background: Sarcoma is a heterogeneous group of malignancies comprising almost 80 subtypes of bone and soft tissue cancers. Previously, all subtypes were managed identically. Advancements in biological and genetic studies have revealed that sarcoma subtypes display varying characteristics and therefore require tailored treatments. Locally advanced soft tissue malignancies of both the trunk and the extremities can present significant challenges for treatment. At present, a negative surgical resection margin is the only definitive treatment despite attempts to use neoadjuvant and adjuvant therapies. In patients with locally advanced non-resectable soft tissue sarcoma (STS), the current practice would advocate amputation. However, studies suggest that limb salvage may be possible with radiotherapy or regional chemotherapy using isolated limb perfusion or isolated limb infusion (ILI). An ideal treatment modality for nonresectable STS would strive for preservation of anatomy and functionality as well as improve quality of life. The aim of the study was to investigate the efficacy of isolated limb infusion as an alternative treatment modality for non-resectable locally advanced STS. Methods: The efficacy of ILI was retrospectively investigated in 10 patients with STS. All patients received ILI with melphalan and actinomycin at the North Estonia Medical Centre Foundation, Tallinn, Estonia from
September 1, 2014 to May 31, 2018. The procedures were performed in a lower extremity in 8 patients and in an upper extremity in 2 patients. The 6-month overall response rate was $78 \%$ and the overall limb salvage rate was $100 \%$. The distant metastatis-free survival was longer for responders than for non-responders. Results and Conclusions: ILI is an alternative treatment modality for regional disease control and limb preservation in patients with cutaneous and soft tissue malignant neoplasms of the extremities. The shortterm response rates are encouraging and the median overall survival shows good results in this highly complex patient population.

(c) 2019 S. Karger AG, Basel

\section{Introduction}

Soft tissue sarcomas (STS) are a rare and histologically diverse group of tumours comprising approximately $1 \%$ of all malignancies in the adult population. Approximately $75 \%$ of all STS develop in the extremities, most commonly in the thigh. They are asymptomatic and therefore often present as large masses by the time of diagnosis. Prognosis is associated with tumour size, depth, histological grade, and anatomical site of the primary lesion [1-4]. Complete surgical resection is currently the only

Data from this manuscript have in part been presented at the 9th Congress of the Baltic Association of Surgeons (Klaipeda, Lithuania; May 10-12, 2018).

\section{KARGER}

() 2019 S. Karger AG, Basel
Dr. Jyri Teras

Centre for Surgical Oncology and General Surgery North Estonia Medical Centre Sytiste 19

13419 Tallinn (Estonia)

E-Mail jyrite@ gmail.com 
universally recognised method of treatment. However, this can be challenging in the case of large tumour sizes and locoregional invasion. Fortunately, the majority of STS subtypes rarely metastasise to the lymph nodes [5].

There are more than 50 histologic subtypes of STS, all of which have differing epidemiology, clinical features, biology, responses to therapy, and prognoses $[2,3,5]$. The aetiology of STS is still unknown. History of previous trauma has been suggested as a predisposing factor but there is little evidence to support this theory. Lymphangiosarcoma is commonly associated with previous radiation in breast cancer and axillary surgery (Stewart-Treves syndrome).

Despite significant developments in the treatment of malignant neoplasms over the last decade, little progress has been made in the systemic therapy of sarcomas. The first-line chemotherapy agent for advanced, metastatic, or non-resectable STS is typically doxorubicin [6]. The combination of doxorubicin with a second drug, such as ifosfamide, represents a valid option for achieving cytoreduction as it induces greater response rates [7]. However, this can have a significant impact on quality of life, with similar overall survival. Hence, a combination therapy should only be used in fit patients requiring cytoreduction after careful discussion regarding the risks and benefits $[7,8]$. In several randomised controlled trials, adjuvant systemic therapies have been tested to reduce the risk of metastatic spread after surgery with or without radiotherapy. Anthracycline-based regimens using doxorubicin as the main chemotherapeutic agent were used in early studies, while more recent trials have tested anthracycline combined with ifosfamide. These treatment strategies offer a survival of $5-10 \%$ which has been considered unsatisfactory when balanced against high-grade toxicity [9].

Locally advanced STS were previously treated with amputations until studies illustrated that this posed a high risk for progressive and metastatic disease with no improved survival rate [2]. The ideal management now is radical surgery with complex reconstruction to achieve limb salvation but this is not clinically feasible in all patients.

When surgical resection is considered inadequate for STS, radiation therapy is recommended. Neoadjuvant radiation is typically a total of 50 Gy delivered in 2-Gy daily fractions over 5 weeks followed by surgery after a 4 - to 6-week recovery period. Adjuvant radiation is commenced approximately 4-6 weeks post surgery or once the wound has adequately healed. This is delivered by daily fractions of 30-33 Gy over 6 weeks to a total of 60-66 Gy $[10,11]$.

Regional chemotherapy is another therapeutic strategy for improving locoregional control of locally advanced STS. Hyperthermic isolated limb perfusion (ILP) was in- troduced as regional therapy for control of locally advanced STS. Several reports have demonstrated limb preservation rates of $58-89 \%$. Isolated limb infusion (ILI) for melanoma was introduced by Dr. John Thompson of the Sydney Melanoma Unit as a minimally invasive alternative for ILP in the late 1990s [2, 12]. ILI has more widely been used in melanoma but now evidence for non-resectable STS is emerging. ILI is non-oxygenated low-flow ILP infused via percutaneous catheters [13]. ILI has proven to be an attractive modality that provides regional disease control and limb preservation in patients with sarcoma of the extremities [14]. Melphalan (L-phenylalanine mustard) has been the standard drug for ILP due to its efficacy and low toxicity profile. With the use of an isolated circuit, drug concentrations in the limb are 20 times higher than it can be systemically achieved. Several attempts have been made to improve the response to ILP by using cytostatic drugs other than melphalan. At present, the only alternative regime is melphalan combined with actinomycin $\mathrm{D}[15]$.

The aim of this study is to analyse the efficacy of ILI in non-resectable locally advanced STS.

\section{Patients and Methods}

Data was retrospectively collected on all patients treated for STS with ILI at the Centre for Surgical Oncology and General Surgery, North Estonia Medical Foundation, Tallinn, Estonia from September 1, 2014 to May 31, 2018. The centre started its ILI programme for unresectable in-transit metastases of malignant melanomas in January 2012 and is the only one in the region providing this therapy.

Patients prospectively gave informed consent for data collection and usage for future clinical research. Patients were referred for regional chemotherapy as palliative treatment for unresectable disease. The decision regarding the treatment modality for STS of the extremities was made by a multidisciplinary cancer team.

10 patients with soft tissue sarcomatoid mass received ILI treatment with melphalan and actinomycin D from September 2014 until May 2018. All patients were evaluated by an experienced group of surgeons as not being candidates for radical resection due to involvement of vital structures. Patients who were radically treated with surgery alone or those who received adjuvant radiotherapy after surgery were not included in the study.

In 8 patients, the procedures were performed in a lower extremity, while 2 patients had disease of the upper limb. There were 6 male and 4 female patients, and the average age at the time of the procedure was 65 years (range 43-90 years). 8 patients underwent ILI for either treatment of inoperable recurrence or palliation, and 2 patients (desmoid fibromatosis and liposarcoma) had the procedure as adjuvant therapy after surgery. Table 1 shows the distribution of patients according to the sarcoma subtypes. 2 patients had a histologically benign disease, i.e. desmoid fibromatosis, which is not considered a sarcoma. However, this is classified as aggressive fibromatosis, and optimal treatment planning therefore requires the involvement of a specialised sarcoma multidisciplinary team such as that in Tallinn [16]. Good efficacy of ILI for desmoid-type fibromatosis has been previously described by several authors [17, $18]$, and therefore these patients were also included in this study. 
Table 1. Patient and tumour characteristics

\begin{tabular}{|c|c|c|c|c|}
\hline Characteristic & Value & & & \\
\hline \multicolumn{5}{|l|}{ Sex, n } \\
\hline Male & 6 & & & \\
\hline Female & 4 & & & \\
\hline Age, years & $65(43-90)$ & & & \\
\hline \multicolumn{5}{|l|}{ Involved limb, $\mathrm{n}(\%)$} \\
\hline Lower & $8(80)$ & & & \\
\hline \multirow[t]{2}{*}{ Upper } & $2(20)$ & & & \\
\hline & Overall $(n=10)$ & Upper limb $(n=2)$ & Lower limb $(\mathrm{n}=8)$ & $\begin{array}{l}\mathrm{p} \text { value (upper } \\
\text { vs. lower limb) }\end{array}$ \\
\hline Limb volume, median & $9.23(2.46$ to 14.69$)$ & $3.3(2.46$ to 4.15$)$ & $10.71(9.5$ to 14.69$)$ & 0.0007 \\
\hline Melphalan dose, median, mg & $50.86(13.6$ to 80.82$)$ & $18.1(13.6$ to 22.6$)$ & 59.04 (44.6 to 80.82$)$ & 0.0046 \\
\hline Actinomycin D dose, median, $\mu \mathrm{g}$ & $450.2(195$ to 500$)$ & $251(195$ to 307$)$ & 500 & $<0.0001$ \\
\hline \multicolumn{5}{|c|}{ Perfusate blood gas, $30 \mathrm{~min}$ ischemia time } \\
\hline $\mathrm{pH}$, median & $7.204(7.106$ to 7.261$)$ & $7.239(7.217$ to 7.261$)$ & $7.196(7.106$ to 7.255$)$ & 0.3294 \\
\hline Base excess, median & $-10.11(-6.2$ to 15.50$)$ & $-9.05(-8.1$ to 10.0$)$ & $-10.38(-6.2$ to 15.50$)$ & 0.5180 \\
\hline $\mathrm{PaO}_{2}$, median, $\mathrm{mm} \mathrm{Hg}$ & $20.59(11.5$ to 31.2$)$ & $17.4(16.8$ to 18$)$ & $21.38(11.5$ to 31.2$)$ & 0.4657 \\
\hline Lactate $\mathrm{mmol} / \mathrm{l}$ & $3.51(2.04$ to 8.29$)$ & $2.3(2.04$ to 2.56$)$ & $3.81(2.1$ to 8.29$)$ & 0.3331 \\
\hline \multicolumn{5}{|l|}{ Soft tissue sarcoma subtype, $n$} \\
\hline Angiosarcoma of soft tissue & 1 & & & \\
\hline Dedifferentiated liposarcoma & 1 & & & \\
\hline Desmoid fibromatosis & 2 & & & \\
\hline Malignant fibrous histiocytoma & 2 & & & \\
\hline Pleomorphic rhabdomyosarcoma & 3 & & & \\
\hline Pleomorphic sarcoma & 1 & & & \\
\hline
\end{tabular}

These locally aggressive soft tissue tumours do not appear to have any potential to metastasise [19]; however, radical surgical treatment is mandatory for desmoid fibromatosis for low local recurrence. Whenever surgery is inadequate, adjuvant therapies or palliative measures have been advised by several studies [16, 17].

The ILI procedure was identically performed in each case by exactly the same surgical team. An identical ILI circuit described by other authors was used $[11,20,21]$. The same ILI method has been used in our centre for treating malignant melanoma in-transit metastases. A schematic diagram of the circuit is illustrated in figure 1 .

High-flow 6F-7F arterial and venous catheters (Bernstein Occlusion Catheter; Boston Scientific ${ }^{\circledR}$, Marlborough, MA, USA) were inserted into the femoral artery and vein under fluoroscopic guidance. The tips of the catheter remained at the level of the elbow or knee joint. No systemic heparinisation was performed during catheter placement. 8 catheters were placed from uninvolved limbs over the aortic and venous arch. 2 patients had catheters inserted ipsilateral to the tumours due to anatomic peculiarities. In the majority of cases $(8 / 10)$, the contralateral approach was preferred, as also previously proposed in many other studies [11, 20, 22]. Most catheters were placed 1 day prior to the ILI procedure due to availability of the angiosuite and catheter placement time (mean time $90 \mathrm{~min}$ ).

All ILI procedures were performed under general anaesthesia. Before anaesthetic induction, the catheters were imaged to ensure that they were correctly positioned and checked to determine patency. If the backflow was inadequate, the catheter tips were withdrawn proximally.

Two temperature probes were placed on the skin, isolated from surroundings with teflon isolation, and connected to the central monitor. A normothermia patient warming system (Bair Hugger $^{\circledR}, 3 \mathrm{M}^{\circledR}$ ) was used. For the involved limb, ILI procedure catheters were connected to form a closed circuit using 3-way stopcocks. A fluid warming system (Ranger ${ }^{\circledR}, 3 \mathrm{M}$ ) was used with a mean output temperature of $41^{\circ} \mathrm{C}$. Before the tourniquet was inflated to $300 \mathrm{~mm} \mathrm{Hg}$, systemic heparinisation was achieved with a heparin dose of $3 \mathrm{mg} / \mathrm{kg}$.

Metastases on the extremity proximal to the tip of the catheter but distal to the tourniquet on the limb were perfused retrograde through the collateral blood vessels. The extent of the perfused tissue was visible after the procedure as an erythematic or often oedematous region.

Chemotherapy was rapidly infused using an infusion pump through the arterial side of the circuit for 5-10 min. It was manually circulated from the venous catheter to the arterial catheter for 30 min by using a $60-\mathrm{ml}$ syringe attached to a three-way tap in the external circuit. Blood gas and acid-base balance analysis were drawn before chemotherapy infusion, $30 \mathrm{~min}$ after the start of the infusion, and immediately after tourniquet removal. The degree of hypoxia and acidosis level were documented.

After $30 \mathrm{~min}$ of infusion the limb was flushed with $1,000 \mathrm{ml}$ of warm isotonic crystalloid solution using a pressurized circuit. Flushed blood was collected from the venous line and discarded. After a washout period the tourniquet was removed and heparinisation was reversed with protamine dosage of $3 \mathrm{mg} / \mathrm{kg}$. The catheters were removed on the same day of the procedure after activated clotting time returned to baseline value.

For the conventional ILP procedure, the suggested melphalan dose is $15-20 \mathrm{mg}$ for smaller limbs and up to $100 \mathrm{mg}$ for larger limbs [23]. Comparable doses were used in our study for the ILI 


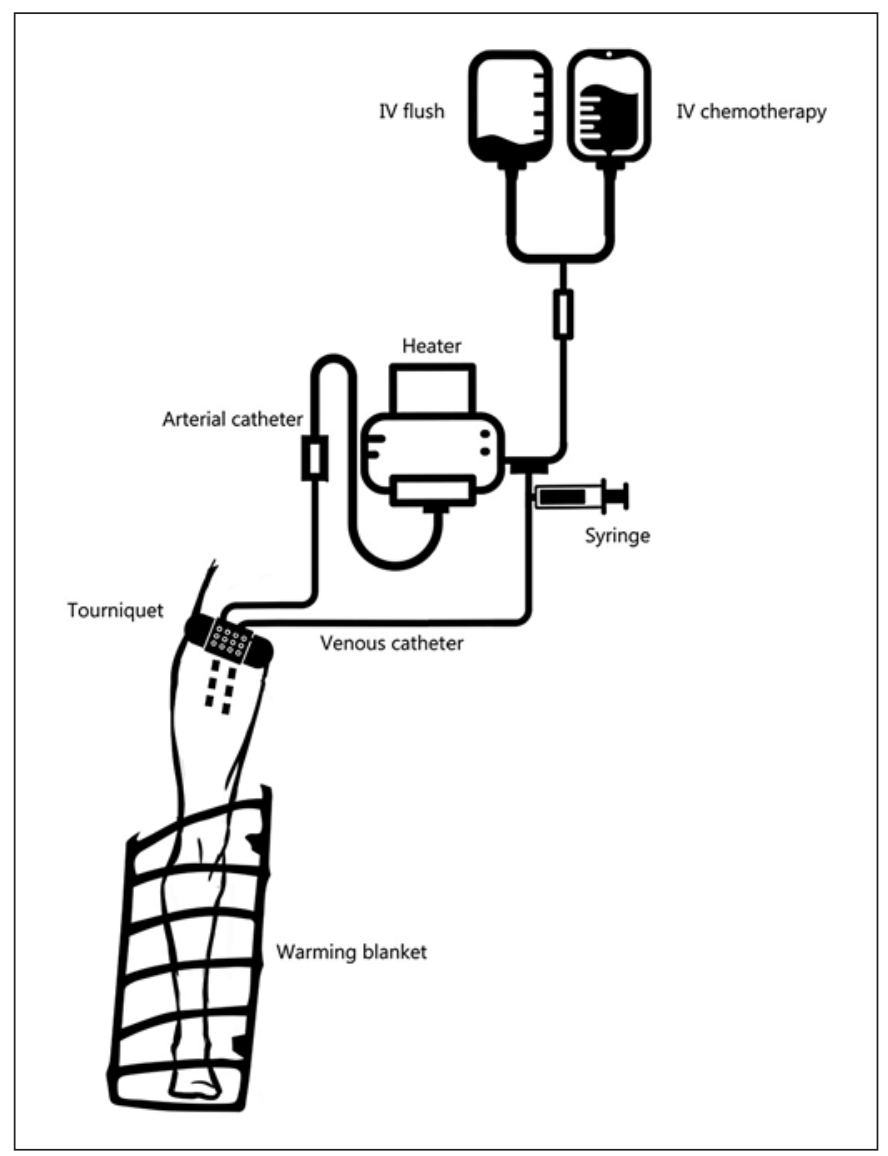

Fig. 1. Schematic diagram of ILI circuit. Chemotherapy is rapidly infused using a pressurised circuit and blood warmer with bubble excluder. Venous blood is manually extracted with a $60-\mathrm{ml}$ syringe and re-injected into the circuit.

procedure in combination with actinomycin D to achieve improved treatment outcomes.

The dose of melphalan was $7.5 \mathrm{mg} / \mathrm{l}$ of limb volume, with a maximum total dose of $80.82 \mathrm{mg}$. Actinomycin D was used at 100 $\mu \mathrm{g} / \mathrm{l}$ of limb volume. Chemotherapy was mixed with heparinised normal saline at $400 \mathrm{ml}$. Limb volume was determined by taking circumferential limb measurements at $1.5-\mathrm{cm}$ intervals and calculated using the Tyler Extremity Volume Calculation program, as per the methodology described by previous studies [24]. Mean limb volume was $10.71 \mathrm{l}$ for lower limbs and $3.3 \mathrm{l}$ for upper limbs. The patient's ideal weight was used to calculate the treatment dosage.

The average melphalan dosage was $50.86 \mathrm{mg}$, and the actinomycin D dosage was $450.2 \mu \mathrm{g}$.

Intraoperative parameters are shown in table 1.

As expected, limb volume and chemotherapy doses were higher in lower limb infusions. A greater degree of acidosis was achieved in the lower limb: the median $\mathrm{pH}$ at $30 \mathrm{~min}$ was 7.196 versus 7.239; however, together with hypoxia levels and base excess reached, the values were not statistically significantly different (median base excess -10.38 vs. -9.05 ). The median $\mathrm{pH}$ at $30 \mathrm{~min}$ was 7.204 , the base excess at $30 \mathrm{~min}-10.11$, and the $\mathrm{PaO}_{2}$ at $30 \mathrm{~min} 20.59$.

\section{Postoperative Care and Toxicity}

Postoperatively, patients were monitored in the recovery unit for $2-3 \mathrm{~h}$ and subsequently transferred to the surgical ward. The mean hospital stay was 15.8 days (range 9-24 days), during which
Table 2. Toxicity according to the Wieberdink grading

\begin{tabular}{llc}
\hline Grade & Description & Value, \% \\
\hline I & No visible toxicity & 0 \\
II & Slight erythema and/or oedema & 60 \\
III & Considerable erythema and oedema with & 40 \\
& blistering & \\
IV & Threatened or actual compartment syndrome & 0 \\
V & Requiring amputation & 0 \\
\hline
\end{tabular}

daily measurements of the serum myoglobin level were carried out. All patients received intravenous hydration with normal saline. High myoglobin levels have been previously reported in several studies $[25,26]$. The myoglobin levels in our series reached as high as $4,107 \mu \mathrm{g} / \mathrm{l}$, with a mean level of $2,013.2 \mu \mathrm{g} / \mathrm{l}$, and a reference value of $19-72 \mu \mathrm{g} / \mathrm{l}$. A rise of myoglobin levels was evident from postoperative day 3 and reached its peak on day 5 , while the decrease started on day 7 and reached normal levels on day 13 .

Toxicity to the ILI was measured and recorded by daily physical examination while hospitalised and for 3 months postoperatively using the scale proposed by Wieberdink et al. [27], which is used in several other studies $[1,25,26]$ and which is presented in table 2 .

As a prophylactic measure, all of the patients were put on lowmolecular-weight heparin on day 1 after the ILI procedure and stayed on treatment until hospital discharge. All patients experienced side effects, the multitude of which were Wieberdink grade II. The most frequent side effects were erythema and swelling of the limb. No limb amputations were required as a consequence of the side effects.

We measured immediate post-procedure limb pain with a visual analogue scale (VAS). Concordance of limb swelling, increase in myoglobin levels, and high VAS score were found (fig. 2).

\section{Statistical Analysis}

All statistical analyses and graphs were performed using JMP 10.0 $\left(\right.$ SAS $\left.^{\circledR}\right)$ and Microsoft Excel software (Microsoft ${ }^{\circledR}$ ).

\section{Outcome Measures}

Cross-sectional imaging using the modified Response Evaluation Criteria in Solid Tumours (RECIST) [28] was used to objectively measure response at 3 months postoperatively and every 6 months thereafter.

None of the patients in this cohort received concurrent treatment between the ILI procedure and the clinical assessment, as this was not deemed necessary by the multidisciplinary cancer board. Accordingly, any tumour response was attributed to the ILI procedure alone. In addition to local tumour response, metastatic-free survival and overall survival were recorded.

In 8 out of 10 patients ( $80 \%)$, successful limb preservation after ILI was observed. 1 patient with pleomorphic sarcoma had limb disease progression 17 months after ILI, declined a second ILI, and underwent above-knee amputation. Another patient with upper limb pleomorphic rhabdomyosarcoma developed axillary metastases together with local progression and underwent shoulder exarticulation 20 months post ILI.

2 patients with lower limb pleomorphic rhabdomyosarcomas developed central progression of the disease 5 and 6 months post ILI, respectively, received systemic chemotherapy, but unfortunately showed no clinical response and died. A third patient in the study population with malignant fibrous histiocytoma (MFH) died due to cardiac arrest 4 months post ILI; no autopsy was performed. Another patient with MFH had an early complete response (6 
Fig. 2. Myoglobin value and VAS pain scale.
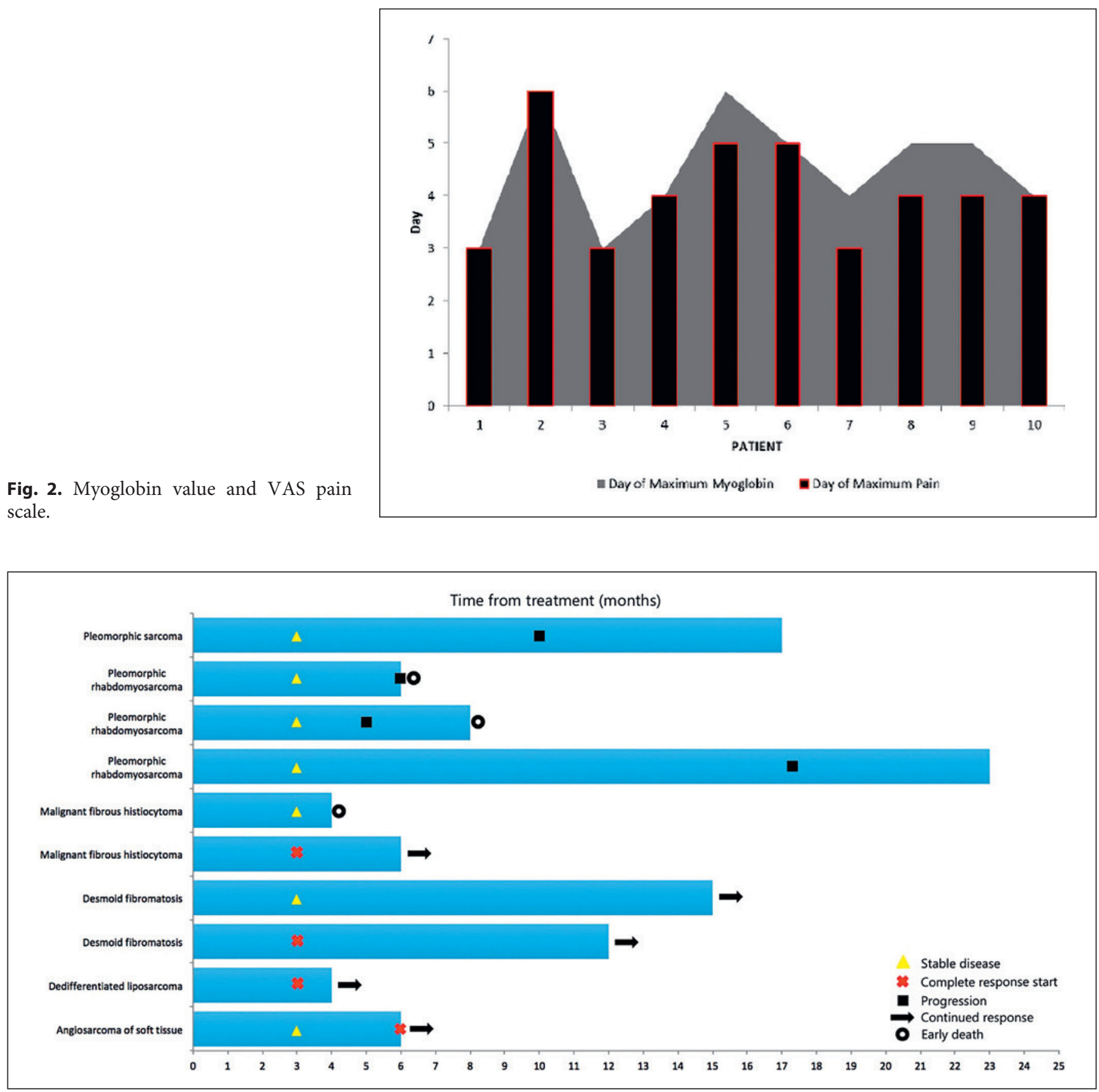

Fig. 3. Characteristics of the study population survival.

months by the time of study completion). Relatively low local recurrence rates for MFH have been described in other studies [13].

Patients with clinically and radiologically stable and progression-free local disease were considered as responders to therapy. The median duration of follow-up was 9.5 months. The overall response rate at 3 months was $100 \% ; 3$ patients (30\%) showed a complete response. At month 6 , however, there were 2 progressions (22\%). Mean distant metastasis-free survival was 8.8 months (range 4-20 months).

An overall response rate of $78 \%$ at month 6 was recorded; complete response was $44 \%$ (4/9), and stable disease was seen in another 3 patients $(33 \%)$.
When 2 patients with desmoid fibromatosis were considered having a benign disease and were thus excluded from survival calculations, then only $42.9 \%(3 / 7)$ had positive response during the follow-up period. Those who developed progression showed signs at 9.5 months post ILI on average (range 5-17 months).

The characteristics of the study population survival are shown in figure 3.

Our study is limited in its evaluation of long-term overall survival; however, the locoregional disease-free interval was 9.5 months on overage (range 5-17 months), but $30 \%$ (3/10) of the patients are still in the early phase of their follow-up period. 


\section{Discussion}

STS are a rare malignant tumour group affecting all age groups. They generally tend to spread along tissue planes, to compressing the surrounding tissues, and typically do not penetrate through anatomic barriers such as the fascia or bone. It is unusual for an STS to invade bone but when it does occur, bone invasion is associated with a significant reduction in overall survival [29]. Every patient with an STS in the extremities requires an individual treatment plan. For optimal treatment outcome, various patient, tumour and anatomic characteristics need to be evaluated in a multidisciplinary setting [11]. The surgical margin has an important impact on outcome because it may be the only independent risk factor that can be influenced by the surgeon in the treatment of an STS of the extremities [30].

Surgical treatment is not always a feasible option; therefore, additional treatment modalities must be available. ILP and ILI have proven to be very effective methods for local disease control in many studies [13, 21, 31].

Notwithstanding the inconsequential patient sample of our study, ILI can still be considered an alternative treatment method for unresectable STS, otherwise treated with amputation. Our data on ILI show a limb salvage rate of $80 \%$, with a mean follow-up of 10.1 months.

For desmoid fibromatosis, a benign disease that clinically often mimics malignancy, the primary treatment option is also radical surgery. However, local control remains a significant problem, with local failure rates of 25 $60 \%$ at 5 years in retrospective studies [16]. We presented two cases of desmoid fibromatosis; one previously had several attempts at radical surgery but with rapid recurrence, while the second patient had ILI done in an adjuvant setting after surgery with a very narrow resection margin. After ILI, both patients had positive outcomes: the first patient has a stable disease with a follow-up period of 15 months, the second has complete response with a follow-up of 12 months.

\section{Conclusion}

STS of the extremities are aggressive but rare malignant tumours that require individualised treatment options discussed in multidisciplinary cancer boards. All treatment modalities should be taken into account when attempting limb salvage without compromising overall survival. A tailored approach should combine radical surgery, systemic therapy, locoregional treatment with radiotherapy, or ILI.

ILI is an alternative treatment strategy for regional disease control and limb preservation in patients with cutaneous and soft tissue malignant neoplasms of the extremities. Despite of the small sample, the short-term response rates for limb salvage are encouraging and good results regarding median overall survival can be found in this highly complex patient population.

\section{Disclosure Statement}

The authors have no conflicts of interest.

\section{References}

1 Tap W, Blay J, Jones R: Treatment Goals and Options in Metastatic STS: Cases and Conundrums. Medscape Education. March 27, 2018. https://www. medscape.org/viewarticle/894350.

2 Turaga K, Beasley G, Kane, J, Delman K, Grobmyer S, Gonzalez R, Letson D, Cheong D, Tyler $\mathrm{D}$, Zager J: Limb preservation with isolated limb infusion for locally advanced nonmelanoma cutaneous and soft-tissue malignant neoplasms. Arch Surg 2011;146:870-875.

3 Mullinax J, Kroon H, Thompson J, Nath N, Mosca P, Farma J, Bhati R, Hardmann D, Sileno S, O'Donoghue C, Perez M, Naqvi S, Chenn A, Gonzales R, Zager J: Isolated limb infusion as a limb salvage strategy for locally advanced extremity sarcoma. J Am Coll Surg 2017;224:635-642.

4 Linehan DC, Brennan MF: Soft tissue sarcoma; in Holzheimer RG, Mannick JA (eds): Surgical Treatment: Evidence-Based and Problem-Oriented. Munich, Zuckschwerdt, 2001. https://www.ncbi.nlm.nih.gov/books/ NBK6952/.
5 Yoon S: The New American Joint Commission on Cancer Staging system for soft tissue sarcomas: splitting versus lumping. Ann Surg Oncol 2018;25:1101-1102.

6 ESMO/European Sarcoma Network Working Group: Soft tissue and visceral sarcomas: ESMO Clinical Practice Guidelines for diagnosis, treatment and follow-up. Ann Oncol 2014;25(suppl 3):iii102-iii112.

7 Savina M, Le Cesne A, Blay JY, Ray-Coquard I, Mir O, Toulmonde M, Cousin S, Terrie P, Ranchere-Vince D, Meerus P, Stoeckle E, Honore C, Sargos P, Sunyach MP, Le Pechoux C, Giraud A, Bellera C, Le Lorer F, Italiano A: Patterns of care and outcomes of patients with METAstatic soft tissue SARComa in a reallife setting: the METASARC observational study. BMC Medicine 2017;15:78.

8 Besiroglu M, Dane F, Ciltas A, Benekli M: Systemic chemotherapy of advanced soft tissue sarcomas. J Oncol Sci 2017;3:66-70.
9 Pasquali S, Gronchi A: Neoadjuvant chemotherapy in soft tissue sarcomas: latest evidence and clinical implication. Ther Adv Med Oncol 2017;9:415-429.

10 Haas R: Managing extremity soft tissue sarcoma patients: surgery alone or in combination with radiotherapy? An editorial on the paper by Fiore et al. Ann Surg Oncol 2018;25: 1461-1462.

11 Ramu E, Houdek MT, Isaac CE, Dickie CI, Ferguson PC, Wunder IS: Management of soft-tissue sarcomas; treatment strategies, staging and outcomes. SICOT J 2017;3:20.

12 Grunhagen DJ, de Witt JH, Graveland WJ, Eggermont AM: The palliative value of tumor necrosis factor $a$-based isolated limb perfusion in patients with metastatic sarcoma and melanoma. Cancer 2006;106:156-162.

13 Moncrieff M, Kroon H, Kam P, Stalley P, Scolyer R, Thompson J: Isolated limb infusion for advanced soft tissue sarcoma of the extremity. Ann Surg Oncol 2008;15:2749-2756. 
14 Vohra N, Turaga K, Gonzale R, Conley A, Reed D, Bui M, Cheong D, Letson D, Zager J: Isolated limb infusion for salvage in limb threatening extremity sarcomas. Int J Hyperthermia 2013;29:1-7.

15 Grünhagen D, Verhoef C: Isolated limb perfusion for stage III melanoma: does it still have a role in the present era of effective systemic therapy? Oncology (Williston Park) 2016;30:1045-1052.

16 Burt R, Viskochill D: Aggressive fibromatosis: a problem for the sarcoma team. http://sarcomahelp.org/articles/fibromatosis.html.

17 Bonvalot S, Desai A, Coppola S, Le Pechoux C, Terrier P, Domont J, Le Cesne A: The treatment of desmoid tumors: a stepwise clinical approach. Ann Surg Oncol 2012;23:156-166.

18 Bonvalot S, Rimareix F, Causeret S, Le Péchoux C, Boulet B, Terrier P, Le Cesne A, Muret J: Hyperthermic isolated limb perfusion in locally advanced soft tisuse sarcoma and progressive desmoid-type fibromatosis with TNF $1 \mathrm{mg}$ and melphalan (T1-M HILP) is safe and efficient. Ann Surg Oncol 2009;16: 3350-3357.

19 Fletcher $\mathrm{CH}$ : Pathology and Genetics of $\mathrm{Tu}$ mours of Soft Tissue and Bone. World Health Organization Classification of Tumours, ed 3. Lyon, IARC Press, 2002.
20 Mian R, Henderson M, Speakman D, Finkelde D, Ainslie J, McKenzie A: Isolated limb infusion for melanoma: a simple alternative to isolated limb perfusion. Canadian J Surg 2001;44:189-192.

21 Brady M, Brown K, Patel A, Fisher C, Marx W: A phase II trial of isolated limb infusion with melphalan and dactinomycin for regional melanoma and soft tissue sarcoma of the extremity. Ann Surg Oncol 2006;13:11231129.

22 Rossi C, Foletto M, Vecchiato A, Alessio S, Menin N, Lise M: Management of cutaneous melanoma M0: state of art and trends. Eur J Cancer 1997;33:2302-2312.

23 Kroon H, Moncrieff M, Kam P, Thompson J: Outcomes following isolated limb infusion for melanoma. A 14-year experience. Ann Surg Oncol 2008;15:3003-3013.

24 Podleska LE, Poeppel T, Herbrik M, Dahlkamp L, Grabellus F, Taeger G: Drug dosage in isolated limb perfusion: evaluation of a limb volume model for extremity volume calculation. World J Surg Oncol 2014;12:81.

25 Rossi C, Foletto M, Pilati P, Mocellin S, Lise $\mathrm{M}$ : Isolated limb perfusion in locally advanced cutaneous melanoma. Semin Oncol 2002;29:400-409.
26 Möller MG, Lewis JM, Desureault S, Zager JS: Toxicities associated with hyperthermic isolated limb perfusion and isolated limb infusion in the treatment of melanoma and sarcoma. Int J Hyperthermia 2008;24:275-289.

27 Wieberdink J, Benckhuysen C, Braat RP, van Slooten EA, Olthuis GA: Dosimetry in isolated perfusion of the limbs by assessment of perfused tissue volume and grading of toxic tissue reactions. Eur J Cancer Clin Oncol 1982;18:905-910.

28 Therasse P, Arbuck S, Eisenhauer E, Wanders J, Kaplan R, Rubinstein L, Verweij J, Van Glabbeke M, van Oosterom A, Christian M, Gwyther S: New guidelines to evaluate the response to treatment in solid tumors. J Natl Cancer Inst 2000;92:205-216.

29 Ferguson PC, Griffin AM, O'Sullivan B, Catton C, Ferguson P, Blackstein M, Kandel RA: Bone invasion in extremity soft-tissue sarcoma: impact on disease outcomes. Cancer 2006;106:2692-2700.

30 Biau DJ, Ferguson PC, Chung P, Griffin AM, Catton CN, O'Sullivan B, Wunder JS: Local recurrence of localized soft tissue sarcoma: a new look at old predictors. Cancer 2012;118: 5867-5877.

31 Wong J, Chen A, Fisher K, Zager J: Isolated limb infusion in a series of over 100 infusions, a single centre experience. Ann Surg Oncol 2013;20:1121-1127. 